http://jmscr.igmpublication.org/home/ ISSN (e)-2347-176x ISSN (p) 2455-0450

crossref DOI: https://dx.doi.org/10.18535/jmscr/v8i2.105

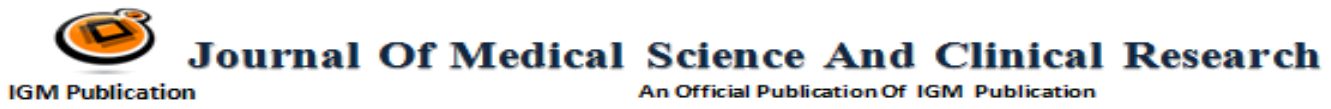

\title{
Microbial Profile of Chronic Otitis Media in Patients of a Tertiary Care Hospital of North Central M.P
}

\author{
Authors \\ Dr Nidhi Sharma ${ }^{1}$, Mrs. Hirdesh Kumari Gupta ${ }^{2}$, Dr Kiran Tripathi ${ }^{3}$ \\ ${ }^{1}$ Asst. Prof. Microbiology, GMC Datia \\ ${ }^{2}$ Tutor, GMC Datia \\ ${ }^{3}$ Prof. \& Head Microbiology, GMC Datia
}

\begin{abstract}
Aim
This study aim to determine commonest microorganism of chronic suppurative otitis media and their antibacterial susceptibility ${ }^{(1)}$ as in chronic otitis media Bacterial infection is often a causes of exacerbation in the clinical course and failure in the treatment. The aim of the study was to determine the incidence and profile of the aerobic bacterial flora in chronic otitis media and to determine the drug susceptibility of isolated bacteria $^{(2) \text {. }}$
\end{abstract}

\section{Material and Method}

A total of 75 patients with unilateral or bilateral active chronic suppurative otitis media attending the OPD Clinic of ENT Dept. from August 2018 to January 2019 were included in the study. All patients were evaluated through detailed history and clinical examination was also done .Patients (males 65, 10 females; mean age 20 - 40 years). Pus sample were collected from the discharging ear(s) with the help of sterile swabs and sent to the hospital laboratory where culture sensitivity studies were done to determine the microbiological profile ${ }^{(3)}$.

\section{Results}

This study was conducted for 6 months from August 2018 to January 2019. Total 75 samples were studied. Among them, 29 (38.66\%) were pure culture and $2(2.66 \%)$ were mixed. Staphylococcus aurerus $16(21 \%)$ was the most common isolate, followed by Pseudomonas aeruginosa $13(17 \%)$ and other isolated microorganisms $5(6.66 \%)$ which included Acinetobacter 2(2.66\%), CONS 2(2.66\%) and Streptococcus pyogenes 1(1.33\%). Drug sensitivity pattern of Staphylococcus aureus showed that Linezolid was active against majority $93.75 \%$, of isolates followed by Vancomycin $81 \%$, Teicoplanin $75 \%$, Tetracycline and Doxycyclin hydrochloride 68\%. Pseudomonas aeruginosa was sensitive to Amikacin $100 \%$ and Ceftazidime 92\%, Meropenem 77\% whereas resistant to Imipenem, Ticarcillin, Clavulanic acid, Tobramicin, Piperacillin, tazobactam in $41 \%$ cases $^{(3)}$.

\section{Discussion}

1. CSOM is described as a condition of middle ear that is characterized by persistent or recurrent discharge through a permanent perforation of the 
tympanic membrane of the middle ear ${ }^{(4)}$. Infection can spread from middle ear to vital structures such as leading to mastoid abscess, facial nerve paralysis, deafness, lateral sinus thrombosis, meningitis, and intracranial abscess With the incidence being very low, they need to be borne in the mind when faced by a patient with active $\mathrm{CSOM}^{(5)}$.Off all the complications, hearing loss associated with chronic ear discharge is nearly always reported in $50 \%$ of cases and tending to be more severe than those reported in other types of otitis media ${ }^{(6)}$. Early bacteriological diagnosis of all cases helps in appropriate and effective therapy and proper selection of antibiotics ${ }^{(5)}$.

2. The culture of pus from ear discharge is affected by patient population, climate, and recent use of antibiotics ${ }^{(7)}$.

3. High prevalence of CSOM in this study was in the age of $20-40$ years $16(51.61 \%)$ followed by age of $0-19$ years $6(19.35 \%)$ unlike our study high incidence of CSOM was found in the age group of 6-10 yrs in studies of Ptigaroo et $\mathrm{al}^{(7)}$ Saini et $\mathrm{al}^{(8)}$ and Nazir and Kadri ${ }^{(6)}$. This may be attributed to late reporting of problem after it becomes chronic, due to lack of knowledge and reluctancy to come to hospital in rural population $^{(6)}$.

4. These days, it is somewhat rare for ENT surgeon, to see ear with discharge that have not already had the bacterial flora modified due to prior antibiotic treatment, since most patients attend the hospital very late when pus cultures are rendered sterile and hence not of any value. This may be attributed to the resistance of the bacteria to these antibiotics there by suggesting their failure, leading to continuous purulent discharge from the ear ${ }^{(9)}$.

5. In this study gender distribution revealed that CSOM was found more common in male $65(86.66 \%)$ than in female $10(13.33 \%)$ consistent

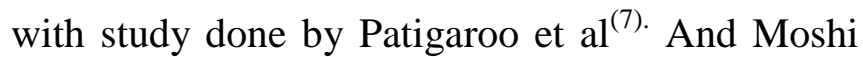
et $\mathrm{al}^{(10)}$. While a study by Nazir and $\mathrm{Kadri}^{(6)}$, Moshi et al ${ }^{(10)}$ and Loy et al ${ }^{(11)}$, Showed a higher incidence in female population as compared to males.
6. In our study $38.66 \%$ were pure growth and $2.66 \%$ were mixed growth and $40 \%$ samples had no growth. Unlike our results ,There are studies by Malkappa et al., ${ }^{(4)}$ Patigaroo et $\mathrm{al}^{(7) ;}$ and Sharma et al., ${ }^{(9),}$ where incidence of sterile growth was least and incidence of pure growth had shown the highest trends.

7. In study done by us S. aureus (21\%) is most common causative agent and P.aeruginosa (17\%)being the $2^{\text {nd }}$ common cause for CSOM. Similarly the study done by Poorey VK and Lyer $\mathrm{A}^{(12),}$ S. aureus $(40.52 \%)$ is most common organism and Pseudomonas aeruginosa(36.7\%), being $2^{\text {nd }}$. Unlike our study, in studies of Fliss et $\mathrm{al}^{(12)}$; Maji et $\mathrm{al}^{(13)}$;Malkappa et $\mathrm{al}^{(4)}$ and Indudharan et $\mathrm{al}^{(14)}, \mathrm{P}$. aeruginosa was the most common organism followed by S.aureus.

8. In our study S. aureus was mainly sensitive to linozolid (93.75\%), vancomycin (81\%), teicoplanin $(75 \%)$, tetracycline and doxycycline hydrochloride $68 \%$ and resistant to norfloxacin. Like our study, study done by Patigaroo et al ${ }^{(7)}$ all MRSA isolates sensitive to linozolid, vancomycin, tetracycline and doxycycline.

Pseudomonas in our study showed maximum sensitivity to amikacin $100 \%$, and ceftazidime $92 \%$ and resistant to imipenum,ticarcillin $41 \%$. Similar results are found in study done by Patigaroo et $\mathrm{al}^{(7)}$ where Pseudomonas spp. were sensitive to amikacin $87 \%$ while resistant to linozolid, vancomycin. In a study done by Loy et al., ${ }^{(11)}$ P.aeruginosa was sensitive to ceftazidime piperacillin and amikacin.

9. Unlike our study, study done by Nazir and kadri $^{(6)}$ the most effective antibiotic against P.aeruginosa was amikacin (92.30\%),followed by piperacillin $(79.48 \%)$, imipenem. this finding was corroborated by study of numerous other author including Mansoor et $\mathrm{al}^{(15) \text {. }}$

\section{Conclusion}

Commonest organisms isolated from chronic discharging ears were Staphylococcus aureus and Pseudomonas aeruginosa. Majority of isolates of Staphylococcus aureus were sensitive to Linezolid 
and resistant to Norfloxacin. Majority of strains of Pseudomonas aeruginosa were sensitive to Amikacin and resistant to Imipenem and Ciprofloxacin $^{(3)}$. Proper knowledge of antibacterial susceptibility of microorganisms will contribute to appropriate and rational antibiotic usage and the successful treatment of chronic suppurative otitis media ${ }^{(1)}$.

\section{References}

1. H Cem Gul, Ali kurnaz, Vedat turhan, O oncul, Alahattin pahsa kulak burun bogaz. Intisasdergisi: $\mathrm{KBB}=$ Joournal of ear, nose $\&$ throat 16(4),164-8,01july2006.

2. A Pajor, $\mathrm{M}$ Disko, $\mathrm{A}$ jankowski, A Bartoszkotyczkowska, R stanczyk.

Otolaryngologia polska $=$ The polish otolaryngology 60(5), 757-63,2006.

3. Muhammad Azeem Aslam, Zafar Ahmed, Raana Azim.journalof the college of physicians and surges Pakistan: JCPSP14(8), 459-61,

4. Malkappa S,kondapaneni S,Surpam R, Chakraverti T. Study of aerobic bacterial isolates and their antibiotic susceptibility pattern in chronic suppurative otitis media. Indian J Otol 2012;18:136.

5. Sanjana R, Singh Y, Reddy N. Aerobic bacteriology of chronic suppurative otitis media (CSOM) in a tertiary care hospital: A retrospective study. Coll Med Sci 2012;7:1-8.

6. Nazir A, Kadri SM. Aerobic bacteriology of chronic suppurative otitis media: A hospital based study. Int J Res Med Sci $2017 ; 2: 15215$.

7. Patigaroo SA, Wani SM, Anjum N, Islam M, Sumbrai D. Ahmad R. drift in the bacteriology of chronic suppurative otitis media and methicillin-resistant staphylococcus aureus as an emerging pathogen: an experience. Int J Med Sci public Health 2016;5:671-7.
8. Saini S, Gupta N, Aparna, Seema, Sachdeva OP. Bacteriological study of paediatric and adult chronic suppurative otitis media. Indian J Pathol Microbiol 2005;48:4136

9. Sharma K, Agarwal A, Khurana PM, comparison of bacteriology in bilaterally discharging ear in chronic suppurative otitis media. Indian J Otolaryngol Head Neck surg 2010;62:153-7.

10. Moshi NH, Minja BM, Ole-Lengine L, Mwakagile DS. Bacteriology of chronic otitis media in Dar es Salaam, Tanzania. East Afr Med J 2000 ;77:20-2.

11. Loy AH,Tan AL, Lu PK.microbiology of chronic suppurative otitis media in singapore. Singapore Med J 2002;43:2969.

12. Poorey VK, Lyer A. study of bacterial flora in CSOM and its clinical significance. Indian J Otolaryngol Head Neck Surg 2002;54:91-5.

13. Fliss DM, Dagan R, Meidan N, Leiberman A.Aerobic bacteriology of chronic suppurative otitis media without cholesteatoma in children. Ann Otol Rhinol Laryngol 1992;101:866-9.

14. Maji PK, Chatterjee TK, Chatterjee S, Chakrabarty J, Mukhopadhyay BB. The investigation of bacteriology of chronic suppurative otitis media in patients attending a tertiary care hospital with special emphasis on seasonal variation. Indian J Otolaryngol Head Neck Surg 2007; 59:128-31.

15. Indudharan R, Haq JA, Aiyar S. antibiotics in chronic suppurative otitis media: A bacteriologic study. Ann Otol Rhinol laryngol 1999;108:440-5.

16. Mansoor T, Musani MA, Khalid G, Kamal M. pseudomonas aeroginosa in chronic suppurative otitis media: sensitivity spectrum against various antibiotics in Karachi. J Ayub Med Coll 2009;21:120-3. 